\title{
Principle and analysis of a linear motor driving system for HTS levitation applications
}

\author{
Jian X. JIN ${ }^{1 *}$, You G. GUO ${ }^{2}$, Jian G. ZHU² \\ ${ }^{1}$ Centre of Applied Superconductivity and Electrical Engineering, University of Electronic Science and Technology of China, Chengdu 610054, China \\ ${ }^{2}$ Faculty of Engineering, University of Technology, Sydney, NSW 2007, Australia
}

Elsevier use only: Received date here; revised date here; accepted date here

\begin{abstract}
High temperature superconductor (HTS) high levitation force density with passive and self-stabilizing features allows a number of special applications to be developed. Linear motor driving systems are commonly required for those applications such as levitated transport systems. In this paper a prototype linear motor driving system with HTS is analyzed with calculation details including its magnetic fields and driving forces presented in the paper. (c) 2001 Elsevier Science. All rights reserved
\end{abstract}

Keywords: High temperature superconductor; levitation; linear motor; magnetic field; magnet

\section{Introduction}

High temperature superconductor (HTS) having levitation force with passive and self-stabilizing features allows a number of special applications to be developed such as frictionless bearings for energy storage flywheels, gyroscopes, momentum wheels, high-speed machine tools, Mag-Lev trains and other levitated transport systems. Linear motor driving systems are commonly required for those applications such as levitated transport systems. In this paper a prototype linear motor driving system using HTS technology is analyzed which has a long active track having three phase windings placed in the side of the track and with the HTS in middle used for the levitation. The phase windings are controlled by an inverter/controller with a single-phase ac supply source. The driving control method is a brushless dc model. Permanent magnets (PM) are employed in the system for the levitation. Analysis and calculation details of magnetic fields and driving forces about the prototype device will be presented in the paper.

\section{Principle configuration}

As shown in Fig.1, a combined HTS driving prototype is designed with long active tracks and 3-phase windings placed in the tracks. Standard 3-phase converters are used with brushless DC control. PMs are mounted on the sides of the moving object. Since the attraction force between the stator and PMs is very large, the motor tracks are beside the mover instead of below the mover. The attraction forces by two sidetracks can be cancelled. The inverter circuit contains the active windings only, facing to the train at a moment, instead of all the windings in the long track.

The design details are as follows: (i) Middle track-HTS/ PM blocks having width $=3 \mathrm{~cm}$, height $=1 \mathrm{~cm}$, and air gap $=0.5 \mathrm{~cm}$; (ii) Main controlled moving body of $20 \times 5 \times 5$ $\mathrm{cm}$; (iii) PMs for levitation on the mover bottom having 20 $\times 2.5 \times 1 \mathrm{~cm}$; (iv) PMs of $1 \times 1 \times 1 \mathrm{~cm}$ for driving on sides of the body, 9 in each side; (v) The dimensions of the stator tooth is $1 \times 1 \times 0.5 \mathrm{~cm}$ (horizontal length); and (vi) The dimensions of a stator slot is $1 \times 1 \times 0.5 \mathrm{~cm}$ (horizontal length).

The dimension of the HTS unit block is $2.5 \mathrm{~cm}$ in diameter and $1 \mathrm{~cm}$ in height having levitation force density is $\sim 12 \mathrm{~N} / \mathrm{cm}^{2}$ when the gap is $0.1 \mathrm{~cm}$.

*Corresponding author. Tel.: +86-028-8320-6390; fax: +86-028-8320-6325; e-mail: jxjin@uestc.edu.cn. 


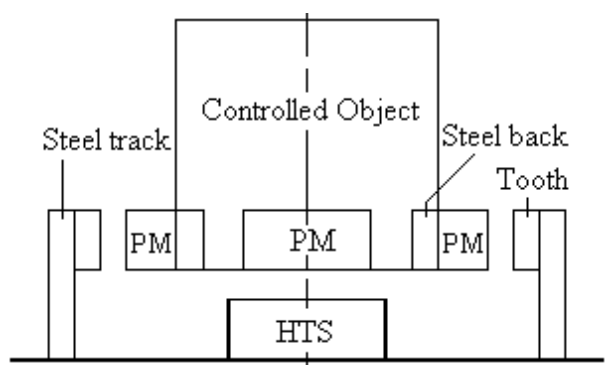

Fig. 1. Schematic diagram of the prototype.

\section{Performance and analysis}

Levitation force is given by

$$
\mathrm{F}_{\mathrm{Lev}}=\iiint_{\mathrm{V}_{\mathrm{SC}}} \mathrm{dV}\left(\mathrm{J}_{\mathrm{SC}} \times \mathrm{B}_{\mathrm{PM}}\right)
$$

where $J_{\mathrm{SC}}$ is the HTS current density, $\mathrm{V}_{\mathrm{sc}}$ is the HTS volume, $\mathrm{B}_{\mathrm{PM}}$ is the PM's flux density.

The controlled object moving speed $\mathrm{v}$ is

$$
\mathrm{v}=\mathrm{m} \tau \mathrm{f}
$$

where $m$ is the phase number, $\tau$ is the pole distance.

Electromagnetic thrust force $\mathrm{F}_{\mathrm{em}}$, when at each moment two phases ( $a$ and $b$ ) are excited (i.e. $i_{a}=-i_{b}, i_{c}=0, E_{a}=-E_{b}$ ):

$$
F_{e m}=\frac{E_{a} i_{a}+E_{b} i_{b}+E_{c} i_{c}}{v}
$$

Motion equation is given by

$$
\frac{\mathrm{dv}}{\mathrm{dt}}=\frac{\mathrm{F}_{\mathrm{em}}-\mathrm{F}_{\mathrm{L}}-\delta_{0} \mathrm{v}}{\mathrm{m}}
$$

where $F_{L}$ is the load, $\delta_{0}$ the friction coefficient, and $m$ the total mass of the moving parts.

2D magnetic field finite element analysis is performed to solve the magnetic field distribution and the maximum PM flux linked to a coil. Considering the structural symmetry, only one pole pitch is required for the field solution. Fig. 2(a) shows the meshes and material codes, where (1) stands for air, (2) and (3) stator coils, (4) and (5) driving PMs, (6) back iron of PMs, and (7) side track iron. Fig. 2(b) illustrates the vector plots of magnetic flux generated by the driving PMs, where the PMs face the stator teeth so that the PM flux of the coil is maximum.

From Fig. 2(b), the maximum flux passing through the coil (the tooth) can be found to be $0.0515 \mathrm{mWb}$ which is calculation result from $\phi_{\text {coil }}=F_{m} /\left(R_{m}+R_{g}\right)$. NdFeB: $H_{c}=950$ $\mathrm{kA} / \mathrm{m}$. When the mover moves, an electromotive force (emf) is induced in the stator windings. Three phase windings, and at any moment, 9 coils (each side) face to the movers. The number of active coils for each phase is 6 . For this case, $\mathrm{E}_{1}=4.44 \mathrm{fN}_{1} \phi_{\text {coil }}=53.2 \times 10^{-3} \mathrm{~V}, \mathrm{v}=3 \mathrm{~m} / \mathrm{s}, \mathrm{F}_{\mathrm{em}}=$ $3.55 \mathrm{~N}$, and $\mathrm{a}=\mathrm{m} / \mathrm{s}^{2}$ (1 kg mass).

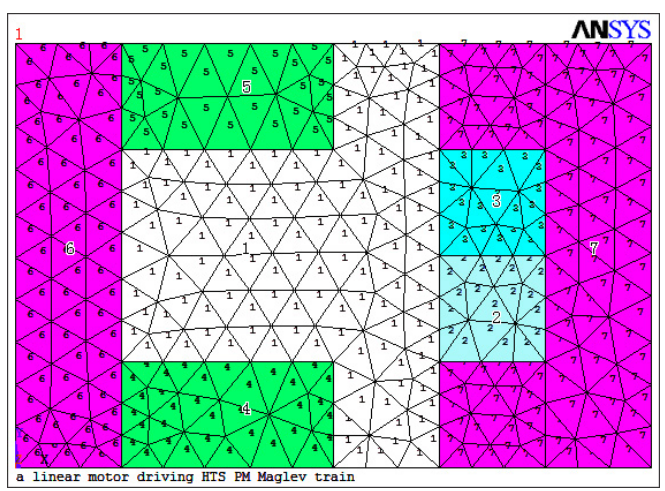

(a)

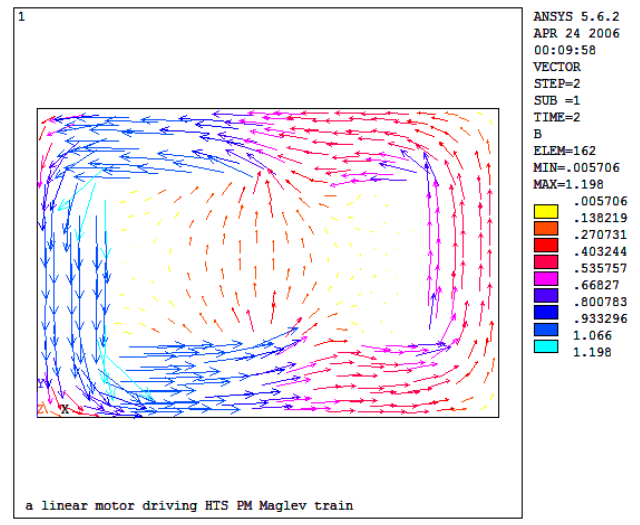

(b)

Fig. 2. Magnetic field finite element analysis. (a) 2D magnetic field FEA mesh and material code; (b) plots of flux density vectors

\section{Conclusion}

Linear motor driving systems have advantages built with HTS. A prototype linear driving system with HTS levitators is analyzed with principle calculations and software simulations. This provides a base for the further development of this HTS linear driving technology.

\section{Acknowledgment}

The author thanks Mr. L.H. Zheng for assistance to the work.

\section{References}

[1] Y. Zhang, S.G. Xu. $15^{\text {th }}$ Int. Conf. Magnet Technology, Oct. 20-24, 1997, Beijing, China, 763.

[2] H. Weh. 15 ${ }^{\text {th }}$ Int. Conf. Magnet Technology, Oct. 20-24, 1997, Beijing, China, 833.

[3] S.Y. Wang, J.S. Wang, J.S. Lian. $15^{\text {th }}$ Int. Conf. Magnet Technology, Oct. 20-24, 1997, Beijing, China, 767. 